\title{
The functional and compositional properties of lipoproteins are altered in patients with metabolic syndrome with increased cholesteryl ester transfer protein activity
}

\author{
KI-HOON PARK ${ }^{1}$, DONG-GU SHIN ${ }^{2}$, JAE-RYONG KIM ${ }^{3}$, JOO-HEON HONG ${ }^{4}$ and KYUNG-HYUN CHO ${ }^{1}$ \\ ${ }^{1}$ School of Biotechnology, Aging-associated Vascular Disease Research Center, Yeungnam University, Gyeongsan, 712-749; \\ ${ }^{2}$ Cardiovascular Division, Internal Medicine, Aging-associated Vascular Disease Research Center, Yeungnam University \\ Medical Center, Daegu, 705-717; ${ }^{3}$ Department of Biochemistry and Molecular Biology, Aging-associated Vascular Disease \\ Research Center, Yeungnam University, Daegu, 705-717; ${ }^{4}$ BioIndustry Center, Daegu Technopark, Daegu 704-801, Korea
}

Received June 15, 2009; Accepted September 17, 2009

DOI: $10.3892 /$ ijmm_00000322

\begin{abstract}
To compare the molecular composition and functional differences at the lipoprotein level, we analyzed individual lipoprotein fractions from male patients with metabolic syndrome (MetS) $(n=10)$ and gender- and age-matched healthy controls $(n=14)$. The MetS group had significantly higher obesity, blood pressure, serum cholesterol, triglyceride (TG), adiponectin, and uric acid levels than the control group, while the serum blood urea nitrogen and creatinine levels of the MetS group were in the normal range. The MetS group had much weaker serum antioxidant ability and were more susceptible to coppermediated low-density lipoprotein (LDL)-oxidation. TG and apoC-III co-accumulated with LDL, high density lipoprotein $(\mathrm{HDL})_{2}$, and $\mathrm{HDL}_{3}$ in the MetS group. The MetS group had serum amyloid A (SAA)-enriched $\mathrm{HDL}_{2}$ and $\mathrm{HDL}_{3}$, although the serum level of SAA was not higher than in controls. The MetS group had significantly deprived paraoxonase (PON) activity in the serum and HDL, while the MetS group had 38\% higher serum cholesteryl ester transfer protein (CETP) activity than that of the control group. Many serum parameters, such as $\mathrm{TG}$, apoC-III, and uric acid, were elevated in the MetS group, and most of these measures were enriched in the LDL and HDL fractions rather than the very low density lipoprotein (VLDL) fraction. The lipid and apolipoprotein composition of HDL was severely altered and its beneficial functions were severely diminished. ApoA-I level was more readily detected in lipoprotein-deficient serum of the MetS group, indicating that the apoA-I exists in a lipid-free state. These results suggest that the MetS group had dysfunctional HDL that enriched TG, apoC-III, CETP, and SAA without antioxidant activity.
\end{abstract}

Correspondence to: Dr Kyung-Hyun Cho, School of Biotechnology, Aging-associated Vascular Disease Research Center, Yeungnam University, Gyeongsan, 712-749, Korea

E-mail: chok@yu.ac.kr

Key words: metabolic syndrome, lipoproteins, antioxidant, cholesteryl ester transfer protein

\section{Introduction}

Metabolic syndrome (MetS) is an independent risk factor for type-2 diabetes and cardiovascular disease, and includes abdominal obesity, hypertriglyceridemia, a low level of highdensity lipoprotein-cholesterol (HDL-C), insulin resistance, and impaired glucose tolerance. The fundamental mechanism for dyslipidemia in MetS may relate to over-secretion, reduced hydrolysis, and impaired clearance of triglyceride rich lipoproteins (TGRL) (1). Therefore, it has been reported that the sera from patients with MetS exhibit an atherogenic dyslipidemia, including elevated serum triglycerides (TG) and very low-density lipoprotein (VLDL) particles, increased small low-density lipoprotein (LDL) particles, and low HDL-C (2). It has been postulated that dyslipidemia influences an alteration of lipoprotein properties, especially the composition of lipids and apolipoprotein, antioxidant ability, and antiatherogenic functions. Since MetS is a major complication of glucose tolerance, obesity, and hypertriglyceridemia, it has been suggested that patients with MetS also suffer from systemic oxidative stress with elevated levels of oxidized LDL (3).

It is well-known that MetS is connected to several pathophysiologic parameters, such as a sedentary life style, obesity, insulin resistance, and dyslipidemia (4). As well as hyperlipidemia, inflammation is a major risk factor of atherosclerosis. Several inflammatory biomarkers, such as hsCRP, cytokines, and biomarkers of endothelial cell activation, have been investigated by other research groups $(5,6)$.

Because lipoprotein metabolism is intimately and mutually related to the progression of metabolic disease, it is possible to speculate that a common metabolic defect causes changes of lipoprotein properties and functions. VLDL and LDL are major carriers of TG and cholesterol, respectively, in the forward cholesterol transport pathway, while HDL is a cholesterol carrier in reverse cholesterol transport. As well as elevated levels of LDL-C, a low level of HDL-C is the most recognized risk factor of dyslipidemia and cardiovascular disease (7), which strongly suggests that the properties of lipoproteins are important biomarkers to evaluate the progression of metabolic disease. However, there have been no reports comparing direct changes in lipoprotein properties with individual fractions in 
patients with MetS regarding the relationship between plasma inflammatory factors, antioxidant abilities, and lipoproteinassociated enzyme activities. In order to compare unique biomarkers between the MetS and control groups, we isolated and analyzed individual lipoprotein fractions (very low density lipoprotein, $\mathrm{LDL}, \mathrm{HDL}_{2}$, and $\mathrm{HDL}_{3}$ ) from sera of patients with MetS patients $(n=10)$ and age- and gender-matched healthy controls $(n=14)$.

\section{Materials and methods}

Subjects. Male patients with MetS $(n=10)$ were recruited according to the following criteria. The patients were first diagnosed and recruited using a modified ATPIII definition of MetS proposed by the National Cholesterol Education Program (2). MetS, defined by ATP-III, requires 3 or more of the criteria linked to insulin resistance, as follows: i) waist circumference $102 \mathrm{~cm}$ (40 inch) in men, ii) TG (>150 mg/dl), iii) HDL-C $(<40 \mathrm{mg} / \mathrm{dl}$ in men), iv) fasting plasma glucose concentration $(>100 \mathrm{mg} / \mathrm{dl})$, and $\mathrm{v}$ ) blood pressure $(>130 / 85 \mathrm{mmHg})$. We excluded cardiovascular disease patients, subjects who consume $30 \mathrm{~g}$ of alcohol/day, subjects who use agents known to affect lipid metabolism, and patients with macroproteinuria, hypothyroidism, and abnormal liver and muscle enzyme levels.

Age- and gender-matched reference subjects $(n=14)$ were recruited from healthy volunteers who attended the Health Center of Yeungnam University Hospital (Daegu, Korea) for regular health examinations. The reference subjects had unremarkable medical records without histories of endocronologic disorders.

Informed consent was obtained from all patients and the reference subjects (control group) prior to enrollment in the study and the Institutional Review Board at the Medical Center of Yeungnam University approved the protocol.

Plasma and lipoprotein analysis. Blood was drawn in an overnight fasting state from all patients and controls. Blood was collected using a vacutainer (BD Sciences, Franklin Lakes, NJ, USA) containing EDTA (final concentration, $1 \mathrm{mM}$ ). Plasma was isolated by low speed centrifugation and each aliquot of plasma was stored at $-80^{\circ} \mathrm{C}$ until analysis.

Blood parameters, lipids, and glucose concentrations were determined using an automatic blood analyzer (Chemistry analyzer AU4500; Olympus, Tokyo, Japan). For each of the lipoproteins (VLDL, $\mathrm{LDL}_{\mathrm{HDL}}$, and $\mathrm{HDL}_{3}$ ) which was purified individually, total cholesterol (TC) and TG measurements were obtained using commercially available kits (cholesterol, T-CHO and TG, Cleantech TS-S; Wako Pure Chemical, Osaka, Japan).

VLDL $(\mathrm{d}<1.019 \mathrm{~g} / \mathrm{ml})$, LDL $(1.019<\mathrm{d}<1.063), \mathrm{HDL}_{2}$ $(1.063<\mathrm{d}<1.125)$, and $\mathrm{HDL}_{3}(1.125<\mathrm{d}<1.225)$ were isolated from individual patient and control sera via sequential ultracentrifugation, with the density being appropriately adjusted by the addition of $\mathrm{NaCl}$ and $\mathrm{NaBr}$ in accordance with standard protocols (8). Samples were centrifuged for $24 \mathrm{~h}$ at $10^{\circ} \mathrm{C}$ at 100,000 x g using a Himac CP-90 $\alpha$ (Hitachi, Tokyo, Japan) at the Instrumental Analysis Center at Yeungnam University.

The protein concentrations of lipoproteins were determined via Lowry protein assay, as modified by Markwell et al (9) and using the Bradford assay reagent (BioRad, Seoul, Korea) with bovine serum albumin (BSA) as a standard.
Ferric reducing ability of plasma assay. The ferric reducing ability of plasma (FRAP) was determined using the method described by Benzie and Strain (10). Briefly, the FRAP reagents were freshly prepared by mixing $25 \mathrm{ml}$ of $0.2 \mathrm{M}$ acetate buffer

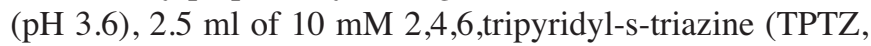
Fluka Chemicals), and $2.5 \mathrm{ml}$ of $20 \mathrm{mM} \mathrm{FeCl}_{3} 6 \mathrm{H}_{2} \mathrm{O}$. The antioxidant activities of the serum were then estimated by measuring the increase in absorbance induced by the generated ferrous ions. The freshly prepared FRAP reagent $(300 \mu 1)$ was mixed with equally diluted serum $(20 \mathrm{mg} / \mathrm{ml}, 10 \mu \mathrm{l})$, after which the ferric reducing ability was determined by measuring the absorbance at $593 \mathrm{~nm}$ every $20 \mathrm{sec}$ over a 10 -min period at $25^{\circ} \mathrm{C}$ using a DU800 spectrophotometer (Beckman Coulter, Fullerton, CA, USA) equipped with a MultiTemp III thermocirculator (Amersham, Uppsala, Sweden).

Copper-mediated LDL-oxidation. To compare the susceptibility of copper-mediated LDL oxidation, $300 \mu \mathrm{g}$ of LDL was incubated with $5 \mu \mathrm{M} \mathrm{CuSO}_{4}$ for up to $3 \mathrm{~h}$. During the incubation, the quantity of formed conjugated dienes was monitored by following the absorbance at $234 \mathrm{~nm}\left(\mathrm{Abs}_{234}\right)$ at $37^{\circ} \mathrm{C}$ (11) using a Beckman DU 800 spectrophotometer equipped with a MultiTemp III thermocirculator.

Paraoxonase assay. Paraoxonase-1 (PON-1) activity toward paraoxon was determined by evaluating the hydrolysis of paraoxon into p-nitrophenol and diethylphosphate, which was catalyzed by the enzyme (12). PON-1 activity was then determined by measuring the initial velocity of p-nitrophenol production at $37^{\circ} \mathrm{C}$, as determined by measuring the absorbance at $405 \mathrm{~nm}$ (microplate reader, BioRad model 680). To accomplish this, the same amount of equally diluted serum $(20 \mathrm{mg} / \mathrm{ml}, 10 \mu \mathrm{l})$ or $\mathrm{HDL}_{3}(2 \mathrm{mg} / \mathrm{ml}, 10 \mu \mathrm{l})$ was added to $200 \mu 1$ of substrate (paraoxon-ethyl, Sigma D-9286; Sigma, St. Louis, MO) containing solution ( $90 \mathrm{mM}$ Tris- $\mathrm{HCl} / 3.6 \mathrm{mM}$ $\mathrm{NaCl} / 2 \mathrm{mM} \mathrm{CaCl}_{2}, \mathrm{pH} 8.5$ ). The PON-1 activity of $1 \mathrm{U} / 1$ was defined as $1 \mu \mathrm{mol}$ of p-nitrophenol formed per minute. The molar extinction coefficient of p-nitrophenol was $17,000 \mathrm{M}^{-1}, \mathrm{~cm}^{-1}$.

Cholesteryl ester transfer assay. An rHDL containing apoA-I and cholesteryl oleate was synthesized in accordance with the method described by Cho et al (13) using trace amounts of $\left[{ }^{3} \mathrm{H}\right]$-cholesteryl oleate (TRK886, $3.5 \mu \mathrm{Ci} / \mathrm{mg}$ of apoA-I; GE Healthcare). Next, to facilitate separation from the CEacceptor, the rHDL was immobilized using a CNBr-activated Sepharose 4B resin (Amersham Biosciences) in accordance with the manufacturer's instructions. The CE-transfer reaction was allowed in $300 \mu 1$ reaction mixtures that contained each of the serum samples $(20 \mu \mathrm{l})$ as a cholesteryl ester transfer protein (CETP) source and rHDL-agarose $(50 \mu 1,0.25 \mathrm{mg} / \mathrm{ml})$ and human LDL $(50 \mu 1,0.25 \mathrm{mg} / \mathrm{ml})$ as a cholesteryl (CE)donor and CE-acceptor, respectively. After incubation at $37^{\circ} \mathrm{C}$, the reaction was halted via brief centrifugation $(10,000 \mathrm{x} \mathrm{g})$ for $3 \mathrm{~min}$ at $4^{\circ} \mathrm{C}$. The supernatant $(150 \mu \mathrm{l})$ was then subjected to scintillation counting, and the percentage transfer of $\left[{ }^{3} \mathrm{H}\right]-\mathrm{CE}$ from rHDL to LDL was calculated.

ELISA, Western blotting, and electrophoresis. For sandwich enzyme linked immunosorbent assay (ELISA), diluted primary antibody $(1: 2,000$ or 1:4,000) was coated onto a 96-well plate 
Table I. Serum profiles of MetS patients and controls.

\begin{tabular}{|c|c|c|}
\hline & $\begin{array}{l}\text { Control } \\
(n=14)\end{array}$ & $\begin{array}{c}\text { Patients } \\
(n=10)\end{array}$ \\
\hline Age (yr) & $65 \pm 8$ & $58 \pm 10$ \\
\hline Body mass index $\left(\mathrm{kg} / \mathrm{m}^{2}\right)$ & $23.1 \pm 2.1$ & $25.2 \pm 0.8^{\mathrm{a}}$ \\
\hline Waist circumference $(\mathrm{cm})$ & $85 \pm 3$ & $94 \pm 9$ \\
\hline Systolic blood pressure $(\mathrm{mmHg})$ & $128 \pm 4$ & $137 \pm 15$ \\
\hline Diastolic blood pressure (mmHg) & $80 \pm 3$ & $85 \pm 10$ \\
\hline Cholesterol (mg/dl) & $196 \pm 31$ & $358 \pm 212^{\mathrm{a}}$ \\
\hline Triacylglycerol (mg/dl) & $103 \pm 40$ & $576 \pm 310^{b}$ \\
\hline HDL-cholesterol (mg/dl) & $54 \pm 13$ & $53 \pm 10$ \\
\hline$\%$ HDL-cholesterol & $28 \pm 7$ & $14 \pm 4^{\mathrm{a}}$ \\
\hline LDL-C & $122 \pm 28$ & $170 \pm 55^{\mathrm{a}}$ \\
\hline TG/LDL ratio & $0.8 \pm 0.3$ & $7.1 \pm 7.8^{\mathrm{a}}$ \\
\hline TC/HDL ratio & $3.7 \pm 1.1$ & $6.4 \pm 2.4^{\mathrm{b}}$ \\
\hline LDL/HDL ratio & $2.3 \pm 0.9$ & $3.2 \pm 0.9^{\mathrm{b}}$ \\
\hline TG/HDL ratio & $2.0 \pm 1.2$ & $18.6 \pm 9.6^{\mathrm{b}}$ \\
\hline T-bilirubin (mg/dl) & $0.9 \pm 0.2$ & $0.6 \pm 0.2$ \\
\hline Alkaline phosphatase (U/l) & $169 \pm 50$ & $166 \pm 14$ \\
\hline GPT (U/l) & $25 \pm 13$ & $32 \pm 13$ \\
\hline GOT (U/l) & $24 \pm 8$ & $31 \pm 15$ \\
\hline hsC-Reactive Protein (mg/l) & $1.3 \pm 0.6$ & $2.1 \pm 0.9^{a}$ \\
\hline White blood cell $(\mathrm{K} / \mu \mathrm{l})$ & $7.8 \pm 2.2$ & $8.3 \pm 3.4$ \\
\hline Red Blood cell $(\mathrm{M} / \mu \mathrm{l})$ & $4.8 \pm 0.4$ & $4.6 \pm 0.5$ \\
\hline Platelet $(\mathrm{k} / \mu \mathrm{l})$ & $263 \pm 69$ & $215 \pm 67$ \\
\hline Serum amyloid A (ng/l) & $563 \pm 232$ & $593 \pm 201$ \\
\hline Glucose (mg/dl) & $93 \pm 23$ & $165 \pm 37^{\mathrm{b}}$ \\
\hline Interleukin-6 (pg/ml) & $71 \pm 24$ & $80 \pm 39$ \\
\hline Apolipoprotein C-III $(\mu \mathrm{g} / \mathrm{ml})$ & $8 \pm 4$ & $11 \pm 4^{\mathrm{a}}$ \\
\hline Apolipoprotein A-I $(\mu \mathrm{g} / \mathrm{ml})$ & $21 \pm 4$ & $31 \pm 5^{\mathrm{a}}$ \\
\hline Uric acid (mg/dl) & $5.8 \pm 1.5$ & $7.4 \pm 1.4^{\mathrm{a}}$ \\
\hline Blood urea nitrogen $(\mathrm{mg} / \mathrm{dl})$ & $17.5 \pm 4.5$ & $15.3 \pm 7.2$ \\
\hline Creatinine (mg/dl) & $0.9 \pm 0.1$ & $1.1 \pm 0.5$ \\
\hline
\end{tabular}

GOT, glutamic oxaloacetic transaminase; GPT, $\gamma$-glutamic pyruvic transaminase; HDL, high-density lipoprotein; LDL, low-density lipoprotein; ${ }^{\mathrm{a}} \mathrm{p}<0.05$ versus control; ${ }^{\mathrm{b}} \mathrm{p}<0.01$ versus control.

(Maxisorp 439454, Nunc, Roskilde, Denmark) overnight at $4^{\circ} \mathrm{C}$. As primary antibodies, apoA-I antibody (Abcam, ab7613) was purchased from Abcam (Cambridge, UK) and apoC-III antibody was obtained from Chemicon (Cat\# AB821; Temecula, CA, USA). Adiponectin antibody was purchased from BD Biosciences (Pharmingen Cat\# A12820). The serum amyloid A (SAA) concentration was determined via a competitive binding ELISA technique, using a commercially available immunoassay kit (Cat\# KNA0012; Biosource, Camarillo, CA, USA) in accordance with the instructions of the manufacturer. Horseradish peroxidase (HRP)-conjugated apoA-I antibody (ab20784) and HRP-apoC-III antibody (ab27624) were purchased from Abcam and used as secondary antibodies. A substrate reagent pack (DY999; R\&D Systems) was used for color development. An equal amount of sample $(20 \mu \mathrm{l})$ was taken from equally diluted lipoprotein fractions as follows: VLDL, $0.6 \mathrm{mg}$ of protein $/ \mathrm{ml}$; LDL, $1.6 \mathrm{mg}$ of protein $/ \mathrm{ml}$; $\mathrm{HDL}_{2}, 0.7 \mathrm{mg}$ of protein $/ \mathrm{ml}$; and $\mathrm{HDL}_{3}, 2 \mathrm{mg}$ of protein $/ \mathrm{ml}$.
Data analysis. All data are expressed as the mean \pm SD. Twogroup comparisons were carried by independent t-tests using SPSS (version 14.0; Chicago, IL, USA). Statistical significance was defined as $\mathrm{p}<0.05$.

\section{Results}

Serum profile. Although the MetS group was mildly overweight (body mass index [BMI], 25.2 $\pm 0.8 \mathrm{~kg} / \mathrm{m}^{2}$ ), the patients had 1.8- and 5.6-fold higher serum TC and TG concentrations compared to the control group (BMI, $23.1 \pm 2.0 \mathrm{~kg} / \mathrm{m}^{2}$ ) as shown in Table I. Although the HDL-C concentration was not different significantly between the groups, the LDL-C concentration was 1.4-fold elevated in the MetS group when compared to the control group. The TG/HDL and TG/LDL ratios were elevated in the MetS group (9.3- and 8.8-fold, respectively) compared to the control group. However, the total bilirubin, alkaline phosphatase, GOT, and GPT values were not different between the groups, and were within the normal ranges. These results indicate that the patients with MetS had not damaged normal hepatic cell function and were without other notable endocronologic diseases. There were no differences in the IL- 6 and SAA concentrations between the groups and they were within the normal ranges, except the MetS group had a 1.6-fold higher hsCRP level that that of the control group. The parameters for kidney function, such as blood urea nitrogen (BUN) and creatinine, were within the normal ranges, except the serum uric acid level was significantly elevated and higher than the normal range in the MetS group $(7.4 \pm 1.4 \mathrm{mg} / \mathrm{dl})$ compared to the control group $(5.8 \pm 1.5 \mathrm{mg} / \mathrm{dl})$. These results indicate that the serum uric acid level can be used as a more reliable prognostic biomarker, although other kidney function parameters were normal in the MetS patients. Interestingly, the serum apoA-I concentration was elevated in the MetS group compared to the control group $(\mathrm{p}<0.05)$ and the serum apoC-III level was slightly higher in the MetS group (Table I). Immunodetection revealed that adiponectin level was $16 \%$ elevated in 20 -fold diluted plasma as shown in Fig. 6 .

Ferric ion reducing ability of plasma. During $20 \mathrm{~min}$ incubation, the plasma of MetS showed much less ferric ion reducing ability compared to control plasma ( Fig. 1A). Up to $20 \mathrm{~min}$ of incubation, the plasma $(10 \mu \mathrm{l})$ of patients with MetS showed $20 \%$ increase in absorbance $593 \mathrm{~nm}\left(\mathrm{~A}_{593}\right)$ from the initial value, while control plasma showed $44 \%$ of increase and PBS showed no increase. This result showed that antioxidant ability was severely decreased in plasma from MetS patients.

Susceptibility of copper-mediated LDL-oxidation. LDL from patients with MetS (MetS-LDL) was more sensitive to coppermediated oxidation than LDL from the control group, as shown in Fig. 1B. Prior to copper addition, LDL from the MetS group had a 1.7-fold higher degree of conjugate diene levels than LDL from the control group, indicating that the LDL was already more oxidized than the control LDL. After $3 \mathrm{~h}$ incubation in the presence of $10 \mu \mathrm{M} \mathrm{Cu}^{2+}$ ion, MetS-LDL showed a $39 \%$ increase in conjugate diene levels compared to the incubation vessel with $\mathrm{Cu}^{2+}$ ion, while control-LDL showed an $8 \%$ increase in conjugated diene levels compared to the 
A

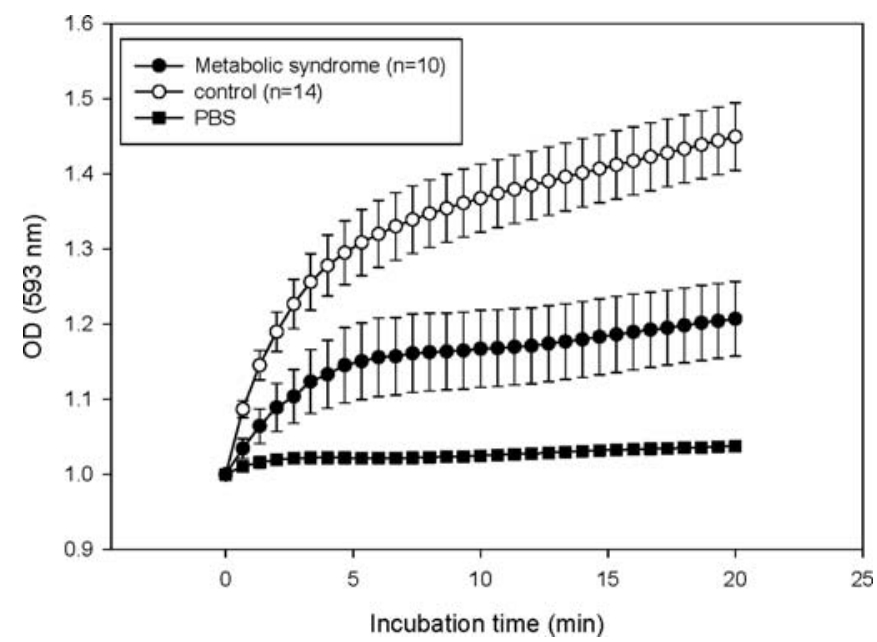

B

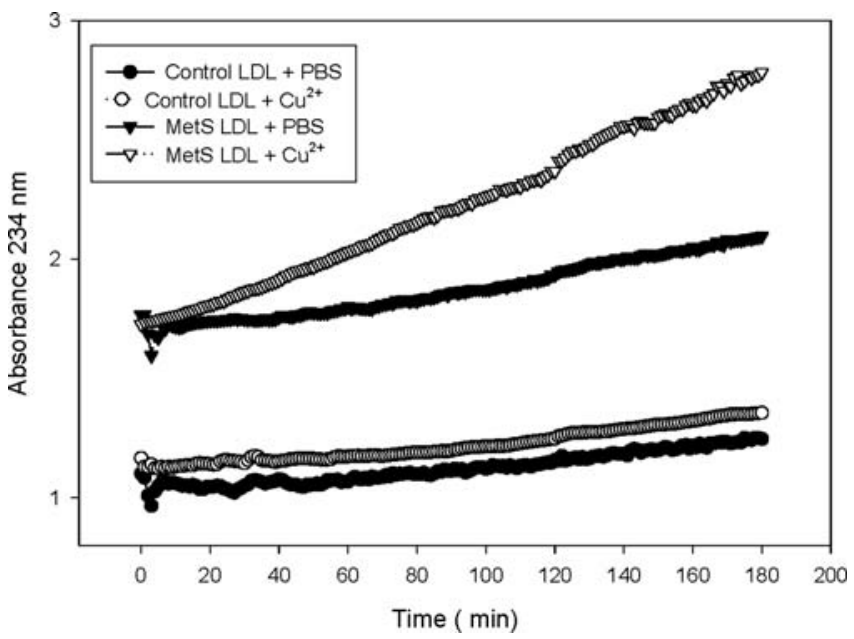

Figure 1. Comparison of the antioxidant ability based on the ferric-reducing ability of plasma (panel A) and LDL oxidation (panel B). (A) Rate of increase in absorbance at $593 \mathrm{~nm}$ of mouse sera. The MetS group showed weaker reducing ability among the groups during 20 min of incubation. (B) Conjugate diene level detection assay at $234 \mathrm{~nm}$ absorbance (Abs234) of copper-mediated LDL-oxidation. The reaction was initiated by the addition of $5 \mu \mathrm{M} \mathrm{CuSO}_{4}$ to the reaction mixture, which contained fresh LDL $(0.3 \mathrm{mg}$ of protein). The data shown represent the mean $\pm \mathrm{SD}$ from three independent measurements. LDL from MetS was more oxidized at the initial reaction time and prone to be easily oxidized.

A

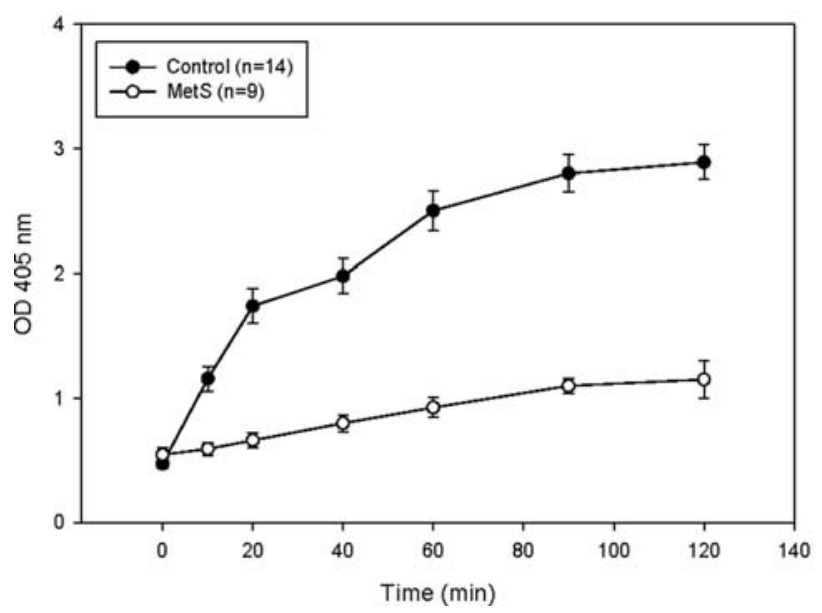

B

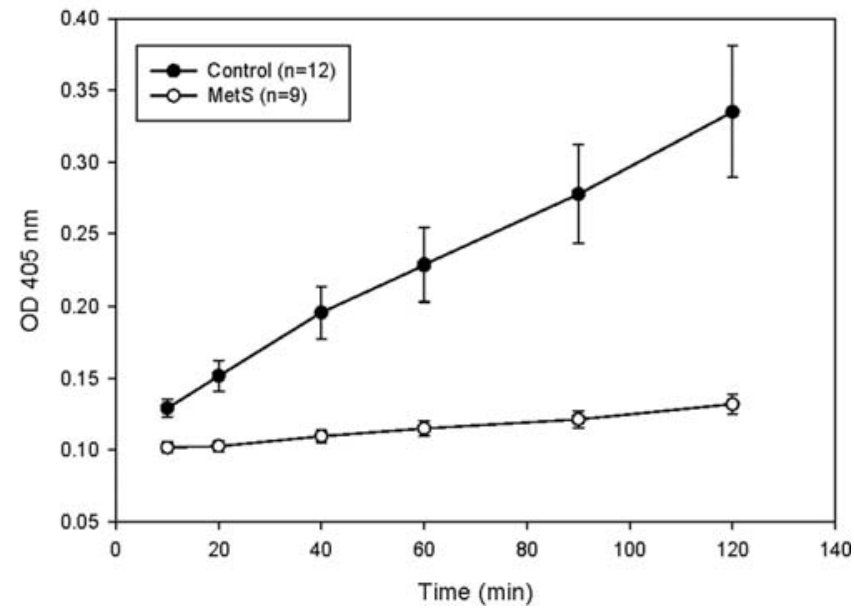

Figure 2. Paraoxonase activity of serum (panel A) and $\mathrm{HDL}_{3}$ (panel B) with time-dependent incubation. Equally diluted serum (20 $\left.\mu 1,20 \mathrm{mg} / \mathrm{ml}\right)$ or $\mathrm{HDL}{ }_{3}(20 \mu 1$, $2 \mathrm{mg} / \mathrm{ml}$ ) was added to $230 \mu \mathrm{l}$ of the paraoxon-ethyl (Sigma Cat\# D-9286) containing solution [90 mM Tris- $\left.\mathrm{HCl} / 3.6 \mathrm{mM} \mathrm{NaCl} / 2 \mathrm{mM} \mathrm{CaCl}{ }_{2}(\mathrm{pH} 8.5)\right]$.

incubation vessel without $\mathrm{Cu}^{2+}$ ion. This result suggests that MetS-LDL was already more oxidized and more prone to be oxidized by copper-mediated oxidation. This result is in agreement with a previous report that MetS is associated with higher levels of circulating oxLDL (3).

Paraoxonase activity was nearly abrogated in the MetS group. Plasma from patients with MetS revealed remarkably decreased PON activity compared to the control group, as shown in Fig. 2A. During 120 min incubation, the MetS group showed 2.1-fold increased PON activity from initial activity, while the control group showed 6.8-fold enhanced activity from the initial value. After $120 \mathrm{~min}$ incubation, the MetS group showed a 2.5-fold lower PON activity than the control group. $\mathrm{HDL}_{3}$ from the MetS group (MetS-HDL 3 ) also exhibited diminished activity during the same time course of incubation as shown in Fig 2B. After a 120 min incubation, MetS-HDL 3 showed 2.5-fold lower PON activity than the control $\mathrm{HDL}_{3}$ when the same amount of protein $(20 \mu \mathrm{g}, 10 \mu \mathrm{l})$ was used.

Lipid profile in lipoprotein species. As shown in Table II, in VLDL, cholesterol was 2-fold more enriched in the MetS than the control group, while the TG level was not different between the two groups. However, TG was well-developed in the MetS group in LDL and HDL compared to the control group. Although the cholesterol content in LDL was slightly higher in the control group, the TG content was 2-fold higher in the MetS group per mg of protein. The MetS group showed 
Table II. Lipid and protein profiles of lipoproteins.

\begin{tabular}{|c|c|c|c|c|c|c|c|c|c|c|c|c|}
\hline & \multicolumn{3}{|c|}{ VLDL (mg/dl) } & \multicolumn{3}{|c|}{$\mathrm{LDL}(\mathrm{mg} / \mathrm{dl})$} & \multicolumn{3}{|c|}{$\mathrm{HDL}_{2}(\mathrm{mg} / \mathrm{dl})$} & \multicolumn{3}{|c|}{$\mathrm{HDL}_{3}(\mathrm{mg} / \mathrm{dl})$} \\
\hline & Chol & TG & Protein & Chol & TG & Protein & Chol & TG & Protein & Chol & TG & Protein \\
\hline $\begin{array}{l}\text { Control } \\
(\mathrm{mg} / \mathrm{mg})\end{array}$ & $\begin{array}{l}28 \pm 9 \\
(0.3)\end{array}$ & $\begin{array}{c}104 \pm 42 \\
(1.2)\end{array}$ & $\begin{array}{c}88 \pm 16 \\
(1.0)\end{array}$ & $\begin{array}{c}228 \pm 34 \\
(0.5)\end{array}$ & $\begin{array}{c}52 \pm 11 \\
(0.1)\end{array}$ & $\begin{array}{c}458 \pm 72 \\
(1.0)\end{array}$ & $\begin{array}{c}48 \pm 20 \\
(0.4)\end{array}$ & $\begin{array}{c}2 \pm 1 \\
(0.02)\end{array}$ & $\begin{array}{c}130 \pm 33 \\
(1.0)\end{array}$ & $\begin{array}{c}106 \pm 34 \\
(0.2)\end{array}$ & $\begin{array}{c}4 \pm 3 \\
(0.007)\end{array}$ & $\begin{array}{c}564 \pm 76 \\
(1.0)\end{array}$ \\
\hline $\begin{array}{l}\text { MetS } \\
(\mathrm{mg} / \mathrm{mg})\end{array}$ & $\begin{array}{l}61 \pm 24^{b} \\
(0.6)\end{array}$ & $\begin{array}{l}98 \pm 25 \\
(1.0)\end{array}$ & $\begin{array}{c}95 \pm 27 \\
(1.0)\end{array}$ & $\begin{array}{c}160 \pm 77 \\
(0.4)\end{array}$ & $\begin{array}{l}78 \pm 20^{\mathrm{a}} \\
(0.2)\end{array}$ & $\begin{array}{c}422 \pm 62 \\
(1.0)\end{array}$ & $\begin{array}{c}36 \pm 9^{a} \\
(0.2)\end{array}$ & $\begin{array}{l}18 \pm 7^{\mathrm{b}} \\
(0.09)\end{array}$ & $\begin{array}{c}195 \pm 46 \\
(1.0)\end{array}$ & $\begin{array}{l}54 \pm 28^{a} \\
(0.1)\end{array}$ & $\begin{array}{l}17 \pm 11^{b} \\
(0.04)\end{array}$ & $\begin{array}{c}428 \pm 87 \\
(1.0)\end{array}$ \\
\hline
\end{tabular}

${ }^{\mathrm{a}} \mathrm{p}<0.05$ versus control; ${ }^{\mathrm{b}} \mathrm{p}<0.01$ versus control; MetS, Metabolic syndrome; TC, total cholesterol; TG, triglyceride; TP, total protein.

A

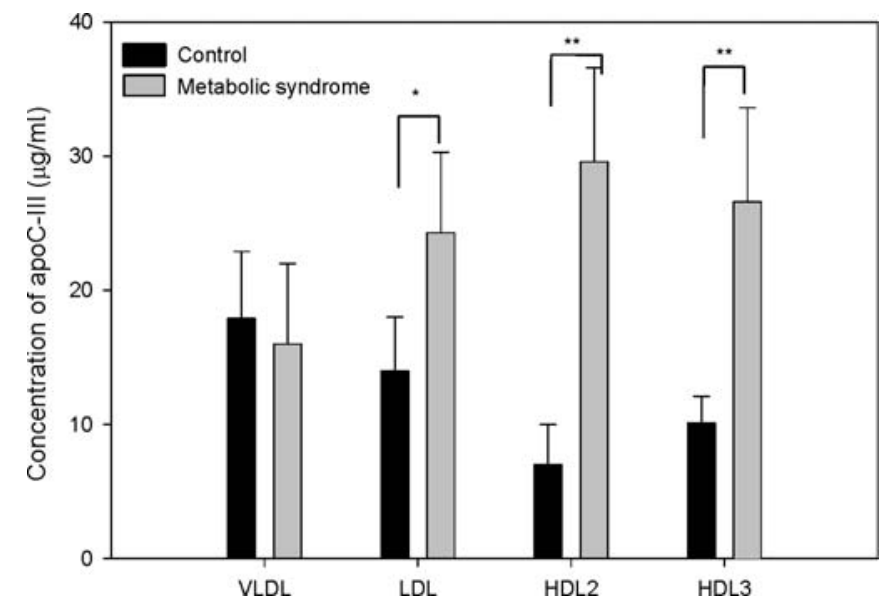

B

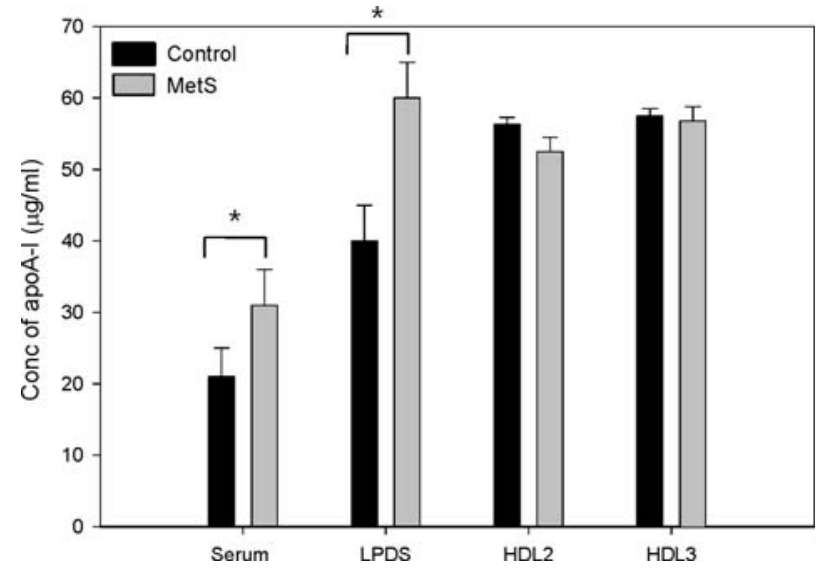

Figure 3. Sandwich ELISA-based detection of apoC-III (panel A) and apoA-I (panel B) in lipoprotein. Individual lipoprotein (50 $\mu 1 ; 2 \mathrm{mg}$ of protein/ml) was reacted with polyclonal apoC-III antibody (AB821) or apoA-I antibody (abcam, ab7613), which was coated on a 96-well plate. In the MetS group, protein levels of apoC-III were highly expressed in the LDL, $\mathrm{HDL}_{2}$, and $\mathrm{HDL}_{3}$ fractions, while the apoA-I level was elevated in serum and lipoprotein-deficient serum (LPDS).

more highly elevated $\mathrm{TG}$ in $\mathrm{HDL}_{2}$ and $\mathrm{HDL}_{3}, 6.0$ - and 5.7-fold higher than that of the control group, respectively. These results suggest that elevated serum TG in patients with MetS accumulated in the LDL and HDL fractions rather than the VLDL fraction.

ApoC-III was elevated in LDL and HDL of the MetS group. ELISA-based quantification revealed that the MetS group had slightly higher levels of serum apoC-III than the control group (Table I). However, all lipoprotein fractions from MetS showed significantly higher apoC-III concentrations than the control group, except the VLDL fraction, as shown in Fig 3A. The MetS group showed a 4.2- and 2.6-fold higher apoC-III level in $\mathrm{HDL}_{2}$ and $\mathrm{HDL}_{3}$, respectively, than that of the control group. Immunodetection also supported the elevation of apoC-III in the MetS group as shown in Fig. 6. These increases of apoC-III in LDL and HDL are well-correlated with elevation of the TG level in the same lipoprotein fraction, as shown in Table II.

ApoA-I was elevated in lipoprotein-deficient serum (LPDS) of the MetS group. ELISA-based determination revealed that MetS had $\sim 1.5$-fold elevated serum apoA-I concentration $(31 \pm 5 \mu \mathrm{g} / \mathrm{ml})$ compared to the control group $(21 \pm 4 \mu \mathrm{g} / \mathrm{ml})$, as shown in Table II. Further analysis with lipoprotein fractions revealed that apoA-I was 1.5 -fold increased in the LPDS ( $\mathrm{d}>1.21$ bottom fraction) of the MetS group than of the control group, as shown in Fig. 3B. Interestingly, however, no difference in the apoA-I amount existed in $\mathrm{HDL}_{2}$ and $\mathrm{HDL}_{3}$ fractions between the two groups, although apoA-I was detected mainly in HDL. These results suggest that the increased apoA-I exists in a lipid-free state rather than a lipid-bound state, such as the HDL fractions.

CE-transfer activity was higher in the MetS group. The MetS group showed superior CE-transfer activity to the control group when plasma and each lipoprotein was used as a CETP source. As shown in Fig. 4, plasma from the MetS group showed significantly elevated CETP activity (29\% CE-transfer from rHDL-agarose to LDL), while the control group showed $21 \%$ CE-transfer activity. LDL (2 mg/ml) from MetS showed 26 $\pm 7 \%$ CE-transfer and $\mathrm{HDL}_{3}(2 \mathrm{mg} / \mathrm{ml})$ from the MetS group showed the highest activity (up to $40 \pm 2 \%$ CE-transfer during a 6-h incubation), while the control group $\mathrm{HDL}_{3}$ showed $29 \pm 1 \%$ CEtransfer. Western blot analysis also revealed a highly elevated level of CETP band in $\mathrm{HDL}_{3}$ fraction from the MetS group as shown in Fig. 6. However, there was no significant difference in CE-transfer activity when $\mathrm{HDL}_{2}$ was used as a CETP source. 


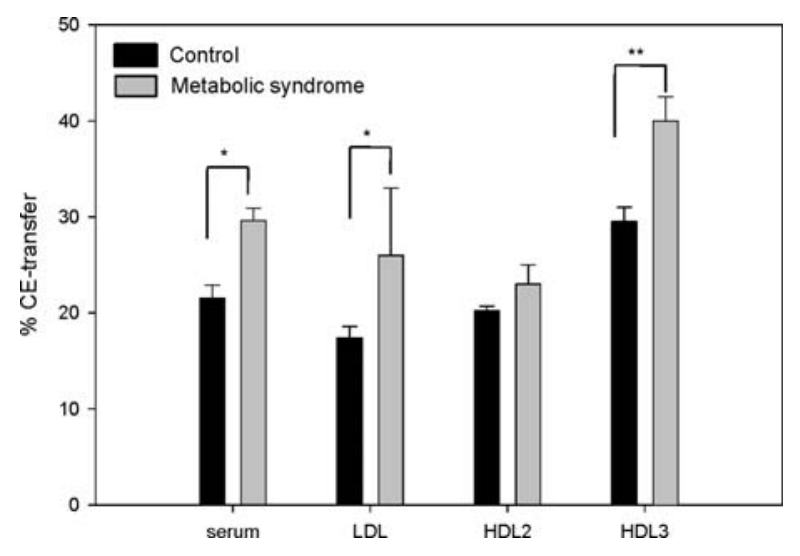

Figure 4. Cholesteryl ester transfer activity. The same amount of protein in individual fraction (100 $\mu \mathrm{g}$ of total protein) was utilized as a source of CETP. Human LDL $(0.25 \mathrm{mg} / \mathrm{ml}$ of protein $)$ and rHDL containing $\left[{ }^{3} \mathrm{H}\right]$-cholesteryl oleate were used as a CE-acceptor and CE-donor, respectively. Error bars indicate the SD from three independent experiments with duplicate samples. " $\mathrm{p}<0.05$ versus control; ${ }^{* *} \mathrm{p}<0.01$ versus control.

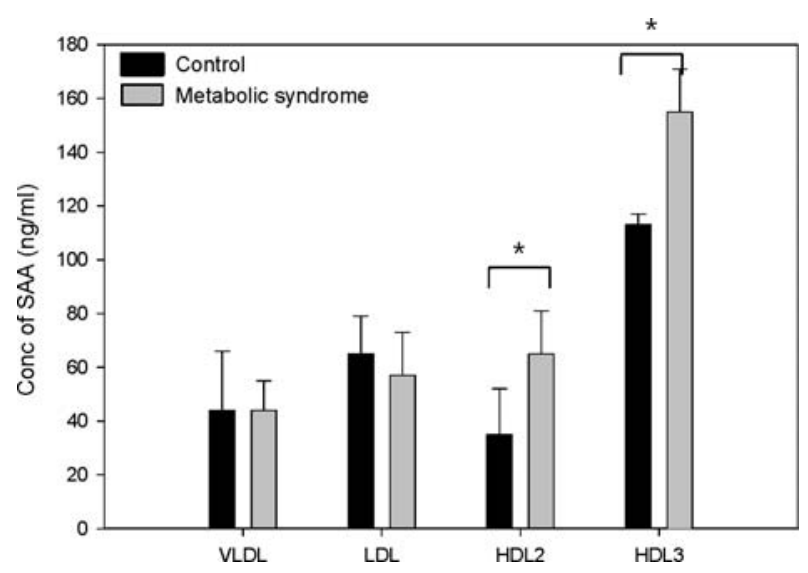

Figure 5. Quantification of serum amyloid A from immunoassays. Equally diluted individual serum $(50 \mu 1)$ (500-fold diluted) and lipoproteins were reacted using an ELISA kit. The concentration was calculated from absorbance at $450 \mathrm{~nm}$, using $630 \mathrm{~nm}$ as a reference. ${ }^{*} \mathrm{p}<0.05$ versus control.

SAA level was elevated in the MetS group. Although the SAA concentration was not significantly different between the two groups, as shown in Table I, there was no remarkable difference in the VLDL and LDL fractions (Fig. 5). However, HDLconjugated SAA content was more readily detected under the same total protein concentrations. In $\mathrm{HDL}_{2}$, the MetS group showed $65 \pm 16 \mathrm{ng} / \mathrm{ml}$, while the control group showed $35 \pm 17 \mathrm{ng} / \mathrm{ml}$. SAA was more readily detected in $\mathrm{HDL}_{3}$, with the MetS group showing $155 \pm 16 \mathrm{ng} / \mathrm{ml}$, while the control group showed $113 \pm 4 \mathrm{ng} / \mathrm{ml}$. Western blot analysis also support elevated level of SAA band intensity in $\mathrm{HDL}_{3}$ from MetS group around $86 \%$ higher than that of control (Fig. 6). This result indicated that SAA was more conjugated in the HDL of the MetS group and showed a greater increase in SAA content in $\mathrm{HDL}_{2}$ and $\mathrm{HDL}_{3}$; SAA was 47 and $28 \%$ increased in $\mathrm{HDL}_{2}$ and $\mathrm{HDL}_{3}$, respectively, from the MetS group compared to the control group $(\mathrm{p}<0.05)$ with the same total protein content.

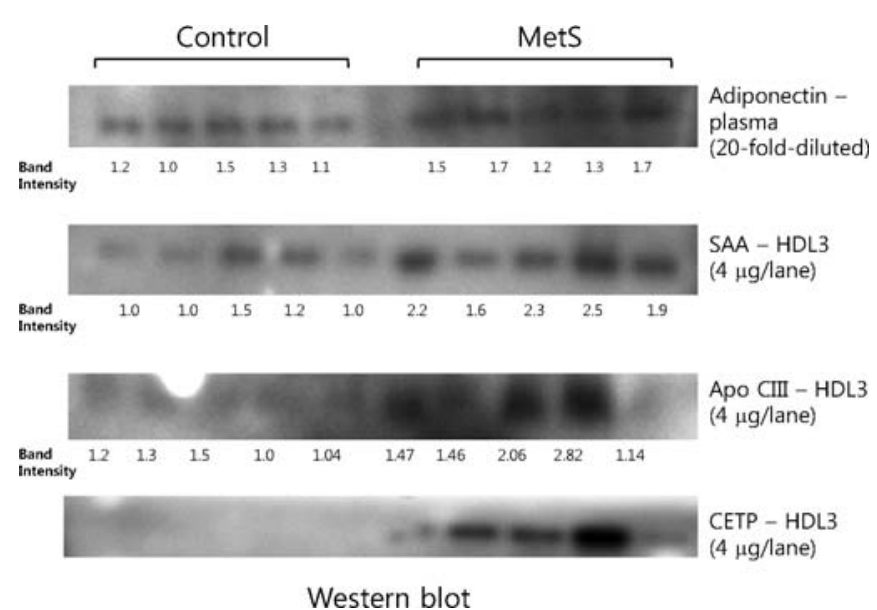

Figure 6. Expressional level of adiponectin in plasma and apolipoproteins in $\mathrm{HDL}_{3}$. Immunodetection with equally diluted plasma and equal amount of $\mathrm{HDL}_{3}(4 \mu \mathrm{g}$ of protein). The lower number indicates the relative band intensity between the groups. SAA, serum amyloid A; CETP, cholestryl ester transfer protein.

\section{Discussion}

Lipid and apolipoprotein composition of serum lipoproteins are relatively susceptible to change under physiologic conditions, especially certain metabolic disease states, acute inflammation, and chronic disorders. Dyslipidemia of MetS has been reported, including elevated TG-rich lipoproteins and subnormal levels of HDL-C, and increased small dense LDL (4). Low HDL-C is a characteristic of atherogenic dyslipidemia and increased cardiovascular risk in patients with metabolic diseases, such as type 2 diabetes and MetS (14).

Although this study was carried out with a small number of participants, this is the first report to compare functional and compositional properties in individual lipoprotein levels between Korean MetS patients and controls. In this study, the MetS patients did not have severe obesity (BMI range, 24.0$26.1 \mathrm{~kg} / \mathrm{m}^{2}$ ), even though they had hypertriglyceridemia and hyperglycemia. It was also revealed that the elevated serum TG is enriched in the $\mathrm{LDL}, \mathrm{HDL}_{2}$, and $\mathrm{HDL}_{3}$ fractions rather than in the VLDL fraction. At least in part, these results are in good agreement with the recent report by the Kontush group, who showed that TG-rich $\mathrm{HDL}_{3}$ appeared in a French patient $(15,16)$. Interestingly and unexpectedly, the TC content of VLDL was 2-fold elevated in the MetS group, although the TG content in VLDL was not higher than in the control group. This result contrasts our recent report that VLDL-TG was abruptly increased in the oliguric phase of a patient with hemorrhagic fever and renal syndrome (17), which allows us to speculate that acute infection and inflammation cause production of TG-enriched VLDL. In this study, however, the VLDL of MetS patients was not related to short-term inflammation, such as viral infections, since the VLDL-TG was not increased and the serum levels of IL-6, GOT, and GPT were not severely increased.

On the other hand, an elevated serum uric acid level has long been recognized as a common feature in patients with MetS (18). Recently, a population-based study revealed that hyperuricemia is well-associated with the incidence of MetS and 
serum uric acid concentrations are significantly correlated with waist circumference in Spanish (19) and Turkish populations (20). In the current study, the Korean MetS group also showed a 1.27-fold higher serum level of uric acid than the control group, as shown in Table I. Coincidentally, Puig et al (19) reported that serum uric acid was increased 1.28 -fold in Spanish MetS patients.

Another interesting finding is that the $\mathrm{C}$ content in $\mathrm{HDL}_{2}$ and $\mathrm{HDL}_{3}$ was significantly decreased in the MetS group, despite a greater protein mass and TG content. This enrichment of TG in HDL might be correlated with the loss of beneficial functions of HDL, such as antioxidant and anti-atherogenic activities. The alterations of lipid distribution have been reported as being strongly correlated to the malfunction of antioxidant ability of HDL and cholesterol efflux. Palmer et al (21) reported that TG-rich lipoproteins inhibit cholesterol efflux to apoA-I from human macrophage foam cells. Similarly, the Morton group reported that the elevated TG content diminishes the capacity of HDL to deliver CE via the SR-BI (22). Recently, our research group also reported that the $\mathrm{HDL}_{2}-\mathrm{C}$ level was decreased and the $\mathrm{HDL}_{2}-\mathrm{TG}$ level was higher in myocardial infarction (MI) patients than in angina pectoris (AP) patients and healthy controls (23). Taken together, an increase of TG in the LDL and HDL fractions could be a highly specific symptom of cardiovascular disease.

However, the MetS group in this study did not show elevated serum IL-6 and SAA levels, while MI patients show elevated IL-6 and SAA levels (23). SAA is able to replace apoA-I in small, dense HDL upon induction of the acute phase. Cabana et al (24) reported that elevated plasma levels of SAA are associated with elevated levels of lipid-free apoA-I, possibly due to the dissociation of apoA-I from HDL. Very similarly, in this report, SAA in $\mathrm{HDL}_{2}$ and $\mathrm{HDL}_{3}$ were remarkably elevated (Fig. 5) and apoA-I in lipoproteindeficient serum was also elevated (Fig. 2). With respect to the change in the levels of expression of apolipoprotein, the different levels of expression of SAA, apoC-III, and apoA-I observed between the two groups depended on the lipoprotein fractions. The apoC-III level was constantly elevated in TG-enriched lipoprotein. However, the current result showed that the apoC-III content in VLDL was not different between the MetS and control groups (Fig. 3A). It is known that apoC-III impairs the lipolysis of TGRL by inhibiting lipoprotein lipase (25), the hepatic uptake of TGRL by the LDL-receptor (26), and vascular endothelial cell dysfunction (27). TG-rich lipoproteins inhibit cholesterol efflux from human macrophage foam cells to lipid-poor apoA-I (21), indicating that the TGRL inhibits arterial reverse cholesterol transport and promote the formation of atherosclerotic lesions. Although VLDL and intermediate density lipoproteins (IDL) were used as TG-rich lipoproteins $(\mathrm{d}=1.006-1.019)$ from the report (21), the results also support that TG-enriched HDL has proatherogenic actions.

The alterations of lipid and protein composition in lipoproteins are linked to proinflammatory changes of lipoproteins, such as the LDL of the MetS group showing a higher conjugated diene level (Fig. 1B) and loss of PON activity (Fig 2). The PON activity was virtually diminished in the plasma and $\mathrm{HDL}_{3}$ from the MetS group, while the control group showed potent activity. These results are in agreement with a previous report (28) that showed small dense lipoprotein particles with reduced PON-1 activity were found in European MetS patients. PON is known as a principal enzyme contributing to antioxidant functions of HDL (12) with arylesterase activity to hydrolyze paraoxon. With those enzyme activities, HDL exerts many beneficial effects for the maintenance of a healthy physiologic system, including antioxidant, -inflammatory, and -thrombotic effects $(29,30)$. Recently, we reported that the $\mathrm{HDL}_{2}-\mathrm{C}$ level was lower and the HDL-TG level was higher in MI patients than angina pectoris (AP) patients, indicating that the alteration of lipid composition in HDL fractions is a typical symptom of MI (23). In insulin resistant states, the elevated serum level and delayed clearance of VLDL particles induces an increased exchange between $\mathrm{CE}$ in $\mathrm{LDL}$ and TG in VLDL, mediated by CETP. This exchange might be associated with the accumulation of LDL particles enriched with TG, as shown in Table II, which are susceptible to be hydrolyzed by hepatic lipase. The consequence is the production of smaller and denser LDL particles, which are easily oxidized and more proatherogenic.

In this study, Korean MetS patients showed more oxidized circulating LDL, decreased paraoxonase of plasma and $\mathrm{HDL}_{3}$, and increased CETP activity of serum and lipoproteins. They also had elevated apoC-III and SAA in HDL fractions and increased apoA-I in lipoprotein fractions. Although they did not show acute inflammatory parameters (hsCRP and IL-6), these alterations in apolipoprotein levels and enzyme activities are correlated well with hypertriglyceridemia and hyperuricemia. These results explain why MetS patients have a primary risk factor for cardiovascular events.

\section{Acknowledgements}

This work was supported by KOSEF, through the Agingassociated Vascular Disease Research Center at Yeungnam University [R13-2005-005-01003-0 (2008)].

\section{References}

1. Chan DC, Watts GF, Barrett PH, Mamo JCL and Redgrave TG: Markers of triglyceride-rich lipoprotein remnant metabolism in visceral obesity. Clin Chem 48: 278-283, 2002

2. National Cholesterol Education Program (NCEP) Expert Panel on Detection, Evaluation, and Treatment of High Blood Cholesterol in Adults (Adult Treatment Panel III): Third Report of the National Cholesterol Education Program (NCEP) Expert Panel on Detection, Evaluation, and Treatment of High Blood Cholesterol in Adults (Adult Treatment Panel III) final report. Circulation 106: 3143-3213, 2002.

3. Holvoet P, Kritchevsky SB, Tracy RP, et al: The metabolic syndrome, circulating oxidized LDL, and risk of myocardial infarction in well-functioning elderly people in the health, aging, and body composition cohort. Diabetes 53: 1068-1073, 2004 .

4. Ruotolo G and Howard BV: Dyslipidemia of the metabolic syndrome. Curr Cardiol Rep 4: 494-500, 2002.

5. Suzuki T, Hirata K, Elkind MSV, et al: Metabolic syndrome, endothelial dysfunction, and risk of cardiovascular events: The Northern Manhattan Study (NOMAS). Am Heart J 156: 405-410, 2008.

6. Rosolova H, Petrlova B, Simon J, Sifalda P and Sipova I: Highsensitivity C-reactive protein and the hypertriglyceridemic waist in patients with type 2 diabetes and metabolic syndrome. Med Sci Monit 14: CR411-CR415, 2008

7. Gotto AM Jr and Brinton EA: Assessing low levels of highdensity lipoprotein cholesterol as a risk factor in coronary heart disease: a working group report and update. J Am Coll Cardiol 43: 717-724, 2004 
8. Havel RJ, Eder HA and Bragdon JH: The distribution and chemical composition of ultracentrifugally separated lipoproteins in human serum. J Clin Invest 34: 1345-1353, 1955.

9. Markwell MA, Haas SM, Bieber LL and Tolbert NE: A modification of the Lowry procedure to simplify protein determination in membrane and lipoprotein samples. Anal Biochem 87: 206-210, 1978.

10. Benzie IF and Strain JJ: The ferric reducing ability of plasma (FRAP) as a measure of antioxidant power: the FRAP assay. Anal Biochem 239: 70-76, 1996.

11. Esterbauer H, Striegl G, Puhl H and Rotheneder M: Continuous monitoring of in vitro oxidation of human low density lipoprotein. Free Radic Res Commun 6: 67-75, 1989

12. Eckerson HW, Wyte CM and La Du BN: The human serum paraoxonase/arylesterase polymorphism. Am J Hum Genet 35: 1126-1138, 1983.

13. Cho KH, Lee JY, Choi MS, Cho JM, Lim JS and Park YB: A peptide from hog plasma that inhibits human cholesteryl ester transfer protein. Biochim Biophys Acta 1391: 133-144, 1998.

14. Maron DJ: The epidemiology of low levels of high-density lipoprotein cholesterol in patients with and without coronary artery disease. Am J Cardiol 86: L11-L14, 2000.

15. De Souza JA, Vindis C, Hansel B, et al: Metabolic syndrome features small, apolipoprotein A-I-poor, triglyceride-rich HDL3 particles with defective anti-apoptotic activity. Atherosclerosis 197: 84-94, 2008.

16. Hansel B, Giral P, Nobecourt E, et al: Metabolic syndrome is associated with elevated oxidative stress and dysfunctional dense high-density lipoprotein particles displaying impaired antioxidative activity. J Clin Endocrinol Metab 89: 4963-4971, 2004.

17. Cho KH, Park SH, Park JE, et al: The function, composition, and particle size of high-density lipoprotein were severely impaired in an oliguric phase of hemorrhagic fever with renal syndrome. Clin Biochem 41: 56-64, 2008

18. Sarafidis PA and Nilsson PM: The metabolic syndrome: a glance at its history. J Hypertens 24: 621-626, 2006.

19. Puig JG and Martinez MA: Hyperuricemia, gout and the metabolic syndrome. Curr Opin Rheumatol 20: 187-191, 2008.

20. Onat A, Uyarel H, Hergenc G et al: Serum uric acid is a determinant of metabolic syndrome in a population-based study. Am J Hypertens 19: 1055-1062, 2006.
21. Palmer AM, Murphy N and Graham A: Triglyceride-rich lipoproteins inhibit cholesterol efflux to apolipoprotein (apo) A1 from human macrophage foam cells. Atherosclerosis 173: 27-38, 2004.

22. Greene DJ, Skeggs JW and Morton RE: Elevated triglyceride content diminishes the capacity of high density lipoprotein to deliver cholesteryl esters via the scavenger receptor class B type I. J Biol Chem 276: 4804-4811, 2001.

23. Cho KH, Shin DG, Baek SH and Kim JR: Myocardial infarction patients showed altered lipoprotein properties and functions when compared with stable angina pectoris patients. Exp Mol Med 28: 67-76, 2009

24. CabanaVG, Lukens JR, Rice KS, Hawkins TJ and Getz GS : HDL content and composition in acute phase response in three species: triglyseride enrichment of HDL a factor in its decrease. J Lipid Res 37: 2662-2674, 1996.

25. Brown VW and Baginsky ML: Inhibition of lipoprotein lipase by an apoprotein of human very low density lipoprotein. Biochem Biophys Res Commun 46: 375-382, 1972.

26. Schayek E and Eisenberg S: Mechanisms of inhibition by apolipoprotein $\mathrm{C}$ of apolipoprotein E-dependent cellular metabolism of human triglyceride-rich lipoproteins through the low density lipoprotein receptor pathway. J Biol Chem 266: 18259-18267, 1991.

27. Kawakami A, Osaka M, Tani M, et al: Apolipoprotein CIII links hyperlipidemia with vascular endothelial cell dysfunction. Circulation 118: 731-742, 2008

28. Garin MC, Kalix B, Morabia A and James RW: Small dense lipoprotein particles and reduced paraoxonase-1 in patients with the metabolic syndrome. J Clin Endocrinol Metab 90: 2264-2269, 2005.

29. Barter PJ, Nicholls S, Rye KA, Anantharamaiah GM, Naval M and Fogelman AM: Antiinflammatory properties of HDL. Circ Res 95: 764-772, 2004

30. Kontush A and Chapman J: Functionally defective high-density lipoprotein: A new therapeutic target at the crossroads of dyslipidemia, inflammation, and atherosclerosis. Pharmacol Rev 58: 342-374, 2006. 